\title{
Economia criativa no Brasil: quadro atual, desafios e perspectivas
}

\author{
Armando Dalla Costa*
}

Elson Rodrigo de Souza-Santos**

\begin{abstract}
RESUMO - A cadeia produtiva da economia criativa no Brasil movimentou em torno de $16 \%$ do PIB em 2006 aparentemente considerado elevado, mas quando se olha o núcleo representava cerca de $2,59 \%$. Este valor ainda é considerado baixo e, em função disso, não é capaz de colocar o país entre os 20 maiores produtores de bens e serviços culturais liderados por China, Estados Unidos e Alemanha. Entretanto, ações de governos, entidades privadas e de ensino e pesquisa começam a colocar as atividades criativas como importantes para o desenvolvimento regional e nacional. Além disso, a economia criativa se apresenta como uma forma de introduzir um novo portfólio de produtos com maior valor agregado e competitivos no mercado internacional ao colocar o capital intelectual como um ativo de competitividade e diferencial no mercado externo.
\end{abstract}

Palavras-chave: Economia criativa. Brasil. Desenvolvimento.

\section{INTRODUÇÃO}

Neste artigo buscamos retomar o tema abordado no trabalho "Economia criativa: novas oportunidades baseadas no capital intelectual”, publicado no Boletim Economia \& Tecnologia na edição de abril/junho de 2011, em que enfatizamos como as características da economia criativa enquanto a criação de riqueza através do capital intelectual e que se dissemina ao longo das cadeias produtivas. Por exemplo, Dowbor (2011) cita que o computador pode ter $95 \%$ do valor em conhecimento incorporado em áreas como design e software tendo os 5\% restantes derivados das dimensões físicas. Desta forma, colocando a criatividade como um fator relevante para o estabelecimento das relações comerciais, competitividade e inserção econômica mundial na medida em que a capacidade de criar passa a ser mais importante do que a produção de commodities e produtos industriais de baixo valor agregado.

O foco do presente trabalho é aprofundar a discussão sobre economia criativa no Brasil enfatizando o quadro atual, as perspectivas e as políticas públicas para o setor vindo na esteira da crescente importância que lhe foi reservada a partir da década de 2000. Acompanhando o movimento internacional de maior atenção às cadeias de produção criativas expressas em

\footnotetext{
* Doutor em História Econômica pela Universidade de Paris III. É professor do Departamento de Economia e no Programa de Pós-Graduação em Desenvolvimento Econômico da Universidade Federal do Paraná. Endereço eletrônico: ajdcosta@ufpr.br.

** Mestre pelo Programa de Pós-Graduação em Desenvolvimento Econômico da Universidade Federal do Paraná. É membro do Núcleo de Pesquisa em Economia Empresarial - NUPEM. Endereço eletrônico: elson129@gmail. com.
} 
relatórios da OCDE (2007) e Unesco (2010), a ponto do governo brasileiro se preocupar em criar a Secretaria de Economia Criativa - SEC, ligada ao Ministério da Cultura, que visa coordenar a estrutura institucional para o crescimento dos setores criativos. Em paralelo, entidades como Instituto de Pesquisa Econômica Aplicada - IPEA, Universidade de São Paulo - USP, Sebrae, Banco Nacional de Desenvolvimento Econômico e Social - BNDES e Federação das Indústrias do Rio de Janeiro - FIRJAN, entre outras, passaram a desenvolver programas e pesquisas sobre o setor.

O trabalho está articulado em duas partes que têm como objetivo fornecer um panorama sobre o que é a economia criativa no país hoje, quais são os desafios e como enfrentálos. A primeira apresenta o quadro da economia criativa no Brasil mostrando como uma área importante da economia brasileira está pulverizada em setores diversos. A segunda aborda as perspectivas, desafios e principais ações em prol do desenvolvimento das atividades criativas no Brasil.

\section{QUADRO ATUAL}

A economia criativa está relacionada ao desenvolvimento da economia e das sociedades modernas atuais na medida em que o capital intelectual se torna cada vez mais relevante para o desenvolvimento de novos produtos e mercados. No Brasil, a partir da década de 2000 as políticas governamentais e a atenção de outras organizações foram despertadas para os setores criativos, acompanhando a maior atenção que surgiu em outros países e entidades internacionais. Um dos pontos altos foi a indicação da brasileira Edna dos Santos-Duisenberg (2011) para o posto mais alto do programa de Economia e Indústrias Criativas das Nações Unidas para Comércio e Desenvolvimento (UNCTAD), que na entrevista dada ao IG, admite o atraso em relação a outros países emergentes como a China, mas ressalta que o país olha com mais atenção para os setores criativos.

Para traçar o quadro da economia criativa no Brasil é necessário tomar como base uma metodologia que identifique os setores criativos e busque os dados capazes de quantificar e qualificar a abrangência das atividades. Uma entidade que patrocinou um estudo nesse sentido foi a FIRJAN (2008), que, apesar de ter como objetivo explorar como o setor criativo poderia contribuir para o desenvolvimento do estado do Rio de Janeiro, acabou por fazer um estudo que abrangesse o Brasil. Inicialmente, a FIRJAN adotou a definição da UNCTAD sobre a delimitação dos setores criativos como "os ciclos de criação, produção e distribuição de bens e serviços que usam criatividade e capital intelectual como insumos primários", identificou a cadeia produtiva e a dividiu em três segmentos (ver Figura 1). 
FIGURA 1 - CADEIA PRODUTIVA DA INDÚSTRIA CRIATIVA

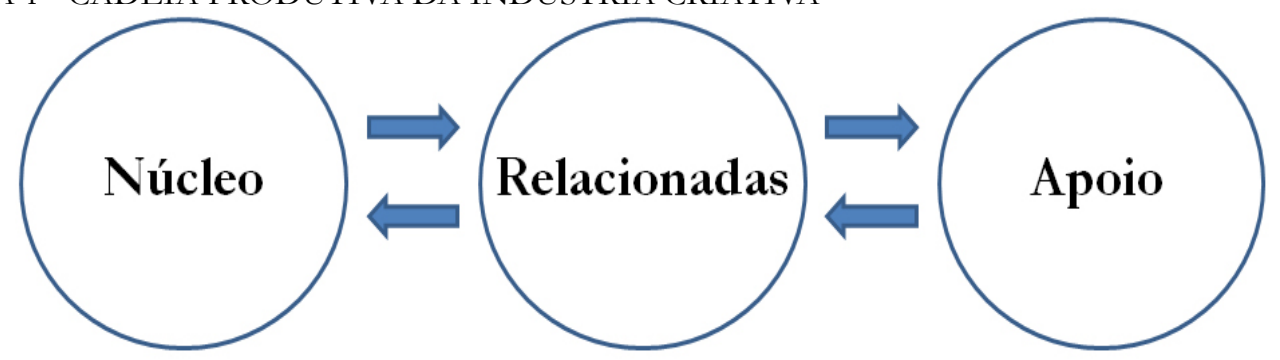

FONTE: FIRJAN (2008, p. 14).

- Núcleo: uma adaptação dos 13 segmentos do estudo britânico, referendados pelo documento da UNCTAD, definido como os segmentos de Expressões culturais, Artes cênicas, Artes visuais, Música, Filme e vídeo, TV e rádio, Mercado editorial, Software e computação, Arquitetura, Design, Moda e Publicidade, constituindo um núcleo composto por serviços com a atividade criativa como parte principal do processo produtivo.

- Relacionadas: envolvendo segmentos de provisão direta de bens e serviços ao núcleo, compostos por indústrias e empresas de serviços fornecedoras de materiais e elementos essenciais para o funcionamento do núcleo.

- Apoio: a provisão de bens e serviços de forma mais indireta que dão suporte ao núcleo e atividades relacionadas.

A partir da definição do que faz parte dos setores criativos, é possível utilizar os dados da Classificação Nacional de Atividades Econômicas (CNAE 2.0) para selecionar entre as 673 classificações possíveis, 185 como relacionadas às atividades criativas. Para quantificar e qualificar a participação dos setores criativos na economia brasileira, utilizam-se dados extraídos da Relação Anual de Informações Sociais - RAIS. O primeiro dado relevante obtido com a pesquisa foi o número de trabalhadores, a renda e a distribuição entre os setores criativos (ver Tabela 1).

Na Tabela 1, as primeiras informações que chamam a atenção são a liderança dos setores de arquitetura e moda no número de trabalhadores (3,3 e 2,3 milhões, respectivamente) e de estabelecimentos (387 e 303 mil, respectivamente), que não é tão surpreendente. A razão é que a arquitetura está relacionada a construção civil, que é um grande negócio, e a moda próxima à indústria têxtil e vestuário. Ambas aplicam fortemente os aspectos criativos do desenvolvimento de produtos, mas estão relacionadas a setores de maior abrangência. 
TABELA 1 - TRABALHADORES E ESTABELECIMENTO DA CADEIA PRODUTIVA DA INDÚSTRIA CRIATIVA NO BRASIL - 2006

\begin{tabular}{|c|c|c|c|c|c|}
\hline $\begin{array}{l}\text { Setores } \\
\text { criativos }\end{array}$ & \begin{tabular}{|c|}
$\begin{array}{c}\text { Número de } \\
\text { trabalhadores } \\
\text { (mil) }\end{array}$ \\
\end{tabular} & \begin{tabular}{|c|}
$\begin{array}{c}\text { Número de } \\
\text { estabelecimentos } \\
(\mathrm{mil})\end{array}$ \\
\end{tabular} & \begin{tabular}{|c|}
$\begin{array}{c}\text { Renda do } \\
\text { trabalho } \\
\text { (R\$ milhões) }\end{array}$ \\
\end{tabular} & \begin{tabular}{|c} 
Renda do \\
trabalhador \\
$(\mathrm{R} \$)$
\end{tabular} & $\begin{array}{c}\text { Trabalhadores } \\
\text { por } \\
\text { estabelecimento }\end{array}$ \\
\hline Arquitetura & $3.305,4$ & 386,5 & $2.642,3$ & 799,0 & 8,6 \\
\hline Moda & $2.320,9$ & 302,6 & $1.513,8$ & 652,0 & 7,7 \\
\hline Design & 704,0 & 70,8 & 812,1 & $1.154,0$ & 9,9 \\
\hline Software & 431,9 & 48,5 & 695,3 & $1.610,0$ & 8,9 \\
\hline Mercado editorial & 371,3 & 52,5 & 408,8 & $1.101,0$ & 7,1 \\
\hline Televisão & 127,6 & 9,3 & 210,0 & $1.646,0$ & 13,7 \\
\hline Filme e vídeo & 120,4 & 20,4 & 107,8 & 895,0 & 5,9 \\
\hline Artes visuais & 82,3 & 2,9 & 132,2 & $1.606,0$ & 28,3 \\
\hline Música & 74,5 & 9,3 & 71,1 & 954,0 & 8,0 \\
\hline Publicidade & 54,4 & 6,0 & 83,0 & $1.526,0$ & 9,0 \\
\hline Expressões culturais & 44,2 & 9,6 & 32,7 & 739,0 & 4,6 \\
\hline Artes cênicas & 11,5 & 2,3 & 11,6 & $1.013,0$ & 5,0 \\
\hline Cadeia da indústria criativa & $7.648,4$ & 920,8 & $6.720,8$ & 879,0 & 8,3 \\
\hline $\begin{array}{l}\text { Parcela da economia } \\
\text { nacional em }(\%)\end{array}$ & 21,8 & 32,5 & 16,3 & 75,1 & 66,9 \\
\hline $\begin{array}{l}\text { Total da economia } \\
\text { nacional }\end{array}$ & $35.155,0$ & $2.834,0$ & $41.117,0$ & $1.170,0$ & 12,4 \\
\hline
\end{tabular}

FONTE: RAIS 2006 e elaboração da FIRJAN (2008).

Em relação a renda por trabalhador se destacam os segmentos de software, televisão, artes visuais e publicidade, pagando em média cerca de $\mathrm{R} \$ 1.500,00$, previsível por serem setores que exigem trabalhadores mais qualificados e diretamente relacionados à produção de bens criativos.

Para a economia nacional, os setores criativos representam $21,8 \%$ do total de trabalhadores de cerca de 35 milhões legalmente contratados e 32,5\% dos estabelecimentos de um universo de 2,8 milhões. A renda representa $16,2 \%$ do total de $\mathrm{R} \$ 41$ bilhões da economia nacional. Desta forma, os números em relação a trabalhadores e renda gerada tornam possível identificar uma grande representatividade da cadeia produtiva na economia brasileira e capacidade de absorção de trabalhadores e outros profissionais. Esta relação fica mais evidente quando comparada em números do PIB (ver Tabela 2).

TABELA 2 - PARTICIPAÇÃO DA CADEIA CRIATIVA NO PIB - 2006

\begin{tabular}{lr|r}
\hline & Valor (em R\$ bi) & Em \% do PIB \\
\hline Núcleo & 60,3 & 2,59 \\
Atividades relacionadas & 125,3 & 5,37 \\
Apoio & 195,7 & 8,39 \\
Total & $\mathbf{3 8 1 , 3}$ & $\mathbf{1 6 , 3 5}$ \\
\hline
\end{tabular}

FONTE: RAIS 2006 e elaboração da FIRJAN (2008).

Em relação ao PIB, o núcleo da cadeia criativa corresponde a cerca de 2,59\%, totalizando cerca de $\mathrm{R} \$ 60$ bilhões, valor relativamente baixo considerando o montante da economia, mas longe de ser desprezível. As atividades relacionadas e de apoio correspondem respectiva- 
mente a 5,37 e 8,39\%, e crescem por não se basearem apenas na economia criativa e são, por isso, mais abrangentes. Considerando a cadeia produtiva como um todo, esta corresponde a 16,35\% do PIB, que em número atinge $\mathrm{R} \$ 381$ bilhões, o que representa uma parcela considerável da produção da riqueza nacional.

Apesar da abrangência da cadeia produtiva ser de 16\% do PIB, a chefe do Programa de Economia Criativa da Conferência das Nações Unidas sobre Comércio e Desenvolvimento UNCTAD, Edna dos Santos-Duisenberg (2011) declarou que a economia criativa no Brasil não figura nem entre as 20 maiores do mundo, lideradas por China, Estados Unidos e Alemanha, e está aquém do que poderia ser. Um dos fatores é considerar o núcleo da economia criativa como ponto central da análise, justificado por ser o centro que impulsiona o avanço da geração de valor da cadeia. Mesmo assim, o setor dá sinais de crescimento, já que as exportações de bens e serviços aumentaram de US\$2,4 bilhões em 2002 para US\$ 7,5 em 2008. Em termos de comparação, a China exportou US\$ 84 bilhões, o que nos aponta um longo caminho a percorrer se quisermos nos aproximar dos líderes.

\section{DESAFIOS E PERSPECTIVAS}

A atenção despertada pela economia criativa na última década encorajou o surgimento de políticas públicas e estudos de instituições diversas para identificar os desafios e problemas e indicar soluções para viabilizar o crescimento desta área. Recentemente, foram identificados quatro grandes desafios para o desenvolvimento das atividades criativas no Brasil, citados por Cláudia Leitão (2011):

1. Levantamento de informações e dados da economia criativa: ausência de pesquisas que contemplem de modo amplo os diversos setores desta economia, permitindo conhecer e reconhecer dados relativos às vocações e oportunidades de empreendimentos criativos para a definição de políticas públicas;

2. Articulação e estímulo ao fomento de empreendimentos criativos: baixa disponibilidade de recursos financeiros para o financiamento de empreendimentos desta natureza; desenvolvimento de tecnologias sociais para a organização em redes e coletivos;

3. Educação para competências criativas: baixo investimento em capacitação dos agentes atuantes nas cadeias produtivas destes setores, agentes cuja atuação exige visão de mercado, capacidade de gestão e conhecimentos técnicos e artísticos; 
4. Produção, circulação/distribuição e consumo/fruição de bens e serviços criativos: pouca infraestrutura no que se refere à produção, circulação/distribuição e consumo/fruição de bens e serviços.

A falta de estudos específicos e dados direcionados à economia criativa é uma dificuldade enfrentada para a construção de políticas públicas e mesmo para a ação de instituições privadas e estratégias empresariais. Trabalhos como o da FIRJAN (2008) são pioneiros ao buscar quantificar e qualificar o que vem a ser a cadeia produtiva no Brasil, mesmo utilizando dados existentes disponíveis na RAIS. Entretanto, os estudos e a disponibilidade de dados precisam ser aprofundados, focados, com maior periodização para dar um panorama sobre as mudanças na cadeia produtiva da indústria criativa, áreas e subáreas e com indicações de como podem ser utilizados para o desenvolvimento regional e local.

A preocupação em dar mais importância e organizar o setor podem ser verificadas em ações como o estudo da FIRJAN (2008), que busca apresentar a economia criativa como um dos caminhos para o desenvolvimento do estado do Rio de Janeiro. Outro exemplo foi a criação da Federação Nacional de Economia Criativa - FNEC, nascida em fevereiro de 2011 com o objetivo de integrar trabalhadores e empreendedores, colocando três objetivos como prioridades para os primeiros anos: capacitação e formação; estudos, pesquisas e políticas públicas; e desenvolvimento regional para permitir a integração das políticas públicas federais (PE360GRAUS, 2011).

Outras entidades começam a criar ações direcionadas à área, como o IPEA (2011), que em novembro de 2011 promoveu a $2^{\circ}$ Conferência de Desenvolvimento ( ${ }^{\circ}$ Code) com objetivo de atrair público para as mídias digitais e economia criativa. Por outro lado, o Sebrae (2011) reservou uma área no site denominada "cultura e entretenimento", para apresentar as novidades da área de economia criativa como um negócio capaz de ser utilizado como forma de inclusão social. A "Cidade do Conhecimento", patrocinada pela USP com apoio financeiro do BNDES, foca nas mídias digitais, constituindo um centro de pesquisa, empresas, instituições públicas e organização da sociedade civil (USP, 2011).

No âmbito federal, a Secretaria da Economia Criativa nasceu da ideia de não ser isolada, mas sim parte de uma articulação maior em relação à ação de outros órgãos e diferentes áreas para promover a rede capaz de dar suporte à economia criativa. Desta forma, Leitão (2011) cita como estrutura de articulação intersetorial dentro do Governo Federal: Ministério do Turismo (turismo cultural/cidades criativas/ bairros criativos); Ministério do Desenvolvimento, Indús- 
tria e Comércio Exterior (design de produto, design de moda, artesanato etc.); Ministério das Comunicações (TVs, rádios, novas mídias etc.); Ministério do Trabalho (capacitação e assistência ao trabalhador criativo); Ministério da Justiça (marcos regulatórios); Ministério da Integração Nacional (bacias e territórios criativos); Ministério da Educação (Capacitação do trabalhador criativo); Ministério das Relações Exteriores (ONU, OMC, OMPI etc.); Ministério da Ciência e Tecnologia (softwares, games eletrônicos, projetos de inovação tecnológica etc.). Entretanto, a integração proposta por Leitão é embrionária, e os diferentes aspectos podem tomar caminhos próprios devido à diversidade de aspectos que a cadeia da economia criativa pode tomar.

Assim, os grandes eventos internacionais programados para o Brasil nos próximos anos, como Copa do Mundo de 2014, Olimpíadas de 2016, outros eventos esportivos de futebol e automobilismo, produções artísticas e turismo, são importantes para desenvolver a economia criativa. Porém, a cadeia produtiva envolve uma ampla gama de bens e serviços que estão pulverizadas na economia, e que estão ligados pela característica de utilizar o capital intelectual como forma de criar algo diferenciado que pode ser comercializado interna e externamente. Ao mesmo tempo, necessitando de uma estrutura institucional que lhe dê suporte, como está expresso no Plano da Secretaria de Economia Criativa 2011-2014 (MINISTÉRIO DA CULTURA, 2011), se colocando como um coordenador de uma ação mais ampla e vendo na economia criativa oportunidade para gerar valor agregado e promover o desenvolvimento nacional e regional.

\section{CONSIDERAÇÕES FINAIS}

A cadeia produtiva no Brasil movimentou em 2006 cerca de 16\% do PIB abrangendo o núcleo, segmentos relacionados e de apoio. Entretanto, o núcleo constitui apenas 2,59\%, representando uma parcela ainda aquém do potencial do país e que não é capaz de colocar o Brasil entre os 20 maiores produtores de bens e serviços criativos no mundo, liderados por China, Estados Unidos e Alemanha. Entretanto, na última década foi observado o crescimento da atenção dispensada ao setor, tanto de instituições privadas, públicas e de ensino e pesquisa, na medida em que o identificam como forma de alavancar o desenvolvimento, o valor agregado e a diversidade dos bens e serviços produzidos na economia brasileira.

Os desafios do desenvolvimento das atividades criativas pairam sobre quatro aspectos: i) carência de estudos e dados aprofundados sobre o setor; ii) necessidade de melhor articulação entre os agentes; iii) formação de mão de obra capacitada; e iv) melhorar a fluidez da produção, distribuição e consumo dos bens e serviços criativos. Como desafios principais podem ser colocados os itens i e ii, na medida em que a cadeia produtiva é importante, mas faltam dados e a 
articulação entre os agentes.

Acompanhado da importância vista nos setores criativos, iniciou-se a busca de dados e estudos sobre os setores criativos, como da FIRJAN (2008), aplicando uma metodologia e definições utilizadas em países como Austrália e Grã-Bretanha, que possuem um setor mais desenvolvido em nome de quantificar e qualificar o que é a economia criativa. $\mathrm{Na}$ articulação institucional, o papel da Secretaria de Economia Criativa, criada em 2011, começa a desenhar um papel importante, mesmo sendo submetida ao Ministério da Cultura, e a ganhar caráter multi-institucional, ao discutir com outros ministérios os diferentes aspectos que envolvem a economia criativa. Em paralelo, a ação de instituições de ensino e pesquisa, como a USP, através da "Cidade do Conhecimento", e a Federação Nacional de Economia Criativa - FNEC, também se manifestam no sentido de promover ações práticas em prol desta atividade.

\section{REFERÊNCIAS}

DALLA COSTA, A.; SOUZA-SANTOS, E. R. de. Economia criativa: novas oportunidades baseadas no capital intelectual. Economia \& Tecnologia, Curitiba, ano 7, v. 25, p. 179-186, abr./jun. 2011.

DOWBOR, L. Capital cognitivo: a economia da criatividade. Le Monde Diplomatique Brasil, São Paulo, ed. 47, jun. 2011.

FIRJAN. A cadeia da indústria criativa no Brasil. In:

to do Rio de Janeiro. n. 2. Rio de Janeiro: FIRJAN, 2008.

LEITÃO, C. Plano da Secretaria da Economia Criativa: políticas, diretrizes e ações 2011-2014. Disponível em: < http://observatoriodadiversidade.org.br/site/\%E2\%80\%9Csomos-um-paiscriativo-nao-um-pais-inovador\%E2\%80\%9D-diz-claudia-leitao/>. Acesso em: 10/11/2011.

IPEA. Ipea Apresenta \#arenaCode, espaço inédito de conferência. Disponível em: <http:// www.ipea.gov.br/portal $/$ index.php?option $=$ com_content\&view $=$ article\&id $=11102 \&$ catid $=4$ \&Itemid $=2>$. Acesso em: 1/11/2011.

MINISTÉRIO DA CULTURA. Plano da Secretaria da Economia Criativa: políticas, diretrizes e ações 2011 a 2014. Brasilia: Ministério da Cultura, 2011.

OCDE. International measurement of the economic and social importance of culture. Disponível em: <http://www.oecd.org/dataoecd/56/54/38348526.pdf>. Acesso em: 5/5/2011.

PE360GRAUS. Federação Nacional da Economia Criativa passa a existir a partir desta sextafeira. Disponível em: <http://pe360graus.globo.com/noticias/brasil/economia/2011/02/24/ NWS,529671,3,272,NOTICIAS,766-FEDERACAO-NACIONAL-ECONOMIA-CRIATIVA-EXISTIR-PARTIR-SEXTA.aspx>. Acesso em: 5/11/2011.

SANTOS-DUISENBERG, E. Temos muito mais a oferecer do que café, suco e minério. Disponível em: < http://economia.ig.com.br/empresas/unctad+temos + muito + mais + a + oferecer + do + que + cafe + suco + e + minerio/n1597039670251.html $>$. Acesso em 16/10/2011.

SEBRAE. Cultura e Entretenimento. Disponível em: <http://www.sebrae.com.br/setor/cultura-e-entretenimento $>$. Acesso em: 10/11/2011. 
UNESCO. Creative economy: Report 2010. Nova York: United Nation, 2010.

USP. Cidade do conhecimento. Disponível em: < http://www.cidade.usp.br/blog/>. Acesso em: 5/11/2011. 
